\title{
Social relationships in a cooperatively polyandrous group of tamarins (Saguinus fuscicollis)
}

\author{
Anne W. Goldizen \\ Department of Biology, University of Michigan, Ann Arbor, MI 48109, USA \\ Received April 12, 1988 / Accepted August 31, 1988
}

Summary. This paper presents detailed data on the social relationships among the adults, and between the adults and young, of a cooperatively polyandrous saddle-back tamarin (Saguinus fuscicollis; Callitrichidae) group studied for one year. Some data are also presented from groups studied in other years. Adult males in the study groups gave more grooming than they received, while the opposite was true for females (e.g. Fig. 1). The two polyandrous males in the main study group were very rarely aggressive to each other, rarely tried to disrupt each others' copulations, groomed each other, and occasionally shared food, suggesting that their relationship was more affiliative than agonistic. Data on grooming (Fig. 2), spatial relationships, and the initiation of copulations suggest that the males of this group may have been somewhat more responsible than the female for the maintenance of male-female relationships. Both males and females performed all forms of parental care except lactation. In the main study group each of the males groomed the offspring and remained in close proximity to them more than did the female (Figs. 3 and 4). These data are compared with existing data on social relationships in bird species that exhibit cooperative polyandry.

\section{Introduction}

In cooperative polyandry two or more males live together with a female, both copulating with her and cooperatively caring for her offspring. This rare mating system has only been documented in about ten bird species (reviewed by Faaborg and Patterson 1981; Oring 1986; Brown 1987), some

Offprint requests to: Department of Ecosystem Management, University of New England, Armidale, N.S.W. 2351, Australia
Asian human groups (reviewed by Crook and Crook 1988; Durham, in press), and a neotropical primate, the saddle-back tamarin (Saguinus fuscicollis) (Terborgh and Goldizen 1985; Goldizen 1987 a). Cooperative polyandry is unusual from an evolutionary perspective for two reasons. First, two or more males share in reproducing with a single female. Second, males invest substantial energy in caring for young which they might not have fathered. In this paper I present data on the social relationships between adults and between adults and young in cooperatively polyandrous $S$. fuscicollis.

Saddle-back tamarins (Callitrichidae) are 350-400 g monkeys inhabiting the Amazonian forest. Callitrichids (tamarins and marmosets) are distinguished from other anthropoid primates by their small size, their habit of frequent twinning (over $75 \%$ of $S$. fuscicollis births in captivity, Gengozian et al. 1978), and the extensive infant care provided by all group members. The ecology and behavior of callitrichids have been reviewed by Sussman and Kinzey (1984), Snowdon and Soini (in press), and Goldizen (1987b).

Groups of $S$. fuscicollis weddelli at my study site in Peru's Manu National Park usually have either monogamous or cooperatively polyandrous mating patterns, though groups with more than one breeding female occur occasionally (Terborgh and Goldizen 1985; Goldizen 1987a). I have proposed the hypothesis that the mating pattern of a saddle-back tamarin group is determined primarily by the number of older offspring still present in the group, because pairs need help in raising infants. This help can be provided either by older offspring or by additional adult males (Goldizen 1987a, 1988). Lone pairs of S. fuscicollis are very rare, and none of the groups that I saw during months when conceptions normally occur consisted of lone pairs (Goldizen 1987a). All group 
members more than one year of age, and sometimes even yearlings, help to carry and feed infants (Terborgh and Goldizen 1985; Goldizen 1987a). A pair's need for extra help with infant care and the help provided by older offspring generated the following predictions: a pair with older offspring (of one or both of them) in their group should mate monogamously, while both members of a pair without such offspring would benefit (though not necessarily equally) from forming a polyandrous trio with another male, because the additional male would then help care for the subsequent infants.

Few data exist on the interactions among polyandrous adults in species exhibiting facultative cooperative polyandry. Since the males in a polyandrous group are competing to father the offspring of a single female, they might be expected to have an antagonistic relationship. This appears to be the case in one facultatively polyandrous bird species, the dunnock (Prunella modularis) (Davies 1983, 1985; Davies and Houston 1986), but not in another, the Tasmanian native hen (Tribonyx mortierii) (Ridpath 1972b). In this paper I describe the relationships between the males, and also between each of the two adult males and the adult female, in a cooperatively polyandrous saddleback tamarin group. The social relationships are described in terms of grooming patterns, aggressive interactions, spatial relationships, and the interactions among group members during copulations.

There are also few quantitative data on offspring care in species exhibiting cooperative polyandry. Here I present data on the relative contributions of adult males and females to several forms of infant care in wild $S$. fuscicollis. The patterns and costs of lactation and infant-carrying in this population are addressed in Goldizen (1987 a), but will also be considered in the Discussion.

The data presented here must be regarded as preliminary, since most of them were collected from only one social group. Nonetheless, this is the first time that some of this information has been collected on cooperatively polyandrous groups in any species. In addition, this work shows that it is possible to collect detailed data on social relationships even in small and secretive forest animals.

\section{Methods}

\section{Study site}

This study occurred in the immediate vicinity of the Cocha Cashu Biological Station, located in tropical moist forest in
Table 1. Compositions of the groups discussed in this paper

\begin{tabular}{|c|c|c|c|c|c|c|}
\hline Group & $\begin{array}{l}\text { Months/ } \\
\text { year }\end{array}$ & $\begin{array}{l}\text { \# of } \\
\text { adult } \\
\text { males }\end{array}$ & $\begin{array}{l}\text { \# of } \\
\text { adult } \\
\text { females }\end{array}$ & $\begin{array}{l}\# \text { of } \\
\text { sub- } \\
\text { adults }\end{array}$ & $\begin{array}{l}\# \text { of } \\
\text { juve- } \\
\text { niles }\end{array}$ & $\begin{array}{l}\text { \# of } \\
\text { infants }\end{array}$ \\
\hline $\mathrm{H}$ & $\begin{array}{c}8-10 / \\
1980\end{array}$ & 4 & 1 & & 2 & $1^{\mathrm{a}}$ \\
\hline $\mathrm{H}$ & $\begin{array}{l}10-11 / \\
1980\end{array}$ & 1 & 1 & & 2 & 1 \\
\hline SW & $\begin{array}{l}9-11 / \\
1980\end{array}$ & 2 & 1 & 1 & 1 & 2 \\
\hline $\mathrm{H}$ & $\begin{array}{c}4-6 / \\
1981\end{array}$ & 1 & 1 & 1 & 1 & \\
\hline SW & $\begin{array}{c}5 / \\
1981\end{array}$ & 1 & 1 & 2 & 1 & \\
\hline SW & $\begin{array}{c}5-10 / \\
1984\end{array}$ & 2 & 1 & & 2 & \\
\hline SW & $\begin{array}{c}11 / 1984 \\
3 / 1985\end{array}$ & 2 & 1 & & 2 & $2^{b}$ \\
\hline
\end{tabular}

a infant born in late September

${ }^{b}$ became juveniles in February 1985

the Manu National Park in southeastern Peru. See Terborgh (1983) for further details.

\section{Field methodology}

A total of 61 S. fuscicollis in seven territories were individually marked between August 1979 and March 1985. Group censuses and behavioral observations were carried out during the following periods: August-November 1979, August-November 1980, March-September 1981, June-August 1982, June-August 1983, and February 1984-March 1985. Unmarked tamarins in the study groups were caught and marked at the beginning of each study period. Trapping and marking methods are described in Terborgh and Goldizen (1985) and Goldizen (1987a). This paper focuses on one group (SW) studied from February 1984 through March 1985, but supporting data are presented from groups studied during earlier periods.

The compositions of the saddle-back tamarin groups described in this paper are shown in Table 1. In the multi-male groups studied in 1980 infants were produced, but I did not know which of the males were reproductively active. In the SW group in 1984 and early 1985 the two adult males mated with the female equally frequently and also did equal amounts of infant-carrying (Goldizen 1987a); this group is considered polyandrous. Only the adult female of that group had been in the SW territory in 1980 or 1981 . The relatedness of the males in the multi-male groups discussed here was not known.

I considered tamarins to be infants up to three months of age (approximate age of weaning), juveniles from three months to one year of age, subadults from one to two years, and adults thereafter. These age classifications are probably conservative, since captive $S$. fuscicollis can reproduce at less than one year of age (Epple and Katz 1980).

\section{Collection of behavioral data}

During 1979 through 1983, habituated groups were followed for over 1100 hours in the H and SW territories, and ecological 
and behavioral data were gathered ad-libitum whenever the animals were observable (Terborgh and Goldizen 1985). During 1984 and 1985 I accumulated 587 hours of observation on the polyandrous SW group, including 236 hours of focal animal sampling (Altmann 1974), and I observed other groups for lesser periods of time.

\section{Allogrooming data}

I recorded allogrooming in each of the study groups whenever I observed it. I defined grooming as one individual picking through the fur of another with its hands for at least five seconds. A grooming bout is defined here as continuous (interrupted for periods of less than one minute) grooming between two individuals without the grooming roles of the participants changing. Grooming bouts were timed to the nearest minute. Since I often missed the beginnings of grooming bouts, their lengths were sometimes underestimated, but this bias should be uniform among all pairs of individuals. A grooming session was a collection of one or more grooming bouts during which no more than fifteen minutes passed with no grooming in the group. Grooming sessions could involve any number of group members.

I calculated three measures of the amount of grooming that one individual (or age-sex class) did to another: the number of grooming sessions during which one individual groomed the other (measure 1), the average number of grooming bouts that one individual groomed the other during grooming sessions when these individuals groomed each other (measure 2), and the average duration of those bouts (measure 3). Because grooming pairs tend to switch grooming roles frequently during grooming sessions, measures 1 and 3 may be better indicators of investment in relationships than measure 2.

I observed 1757 grooming bouts in the 1984-85 SW group and a combined total of 385 bouts in the 1980 and 1981 study groups. Because of the smaller sample size in 1980 and 1981 I combined the data from the groups studied in those years and compared the patterns of grooming by age-sex class, rather than by individual, as I did for the 1984-85 SW group.

\section{Data on nearest neighbors and the spatial dispersion of group members}

I collected data on nearest neighbors and the spatial dispersion of group members during focal samples on the SW group members during four sampling periods in 1984. During May 1-14 and June 14-July 1, I did a total of 68 half-four focal samples on adult male 1,58 on adult male 2 , and 65 on the female. During September 20-October 11 and December 15-28, I did 50 on male 1,47 on male 2,57 on the female, 39 on juvenile male 1 , and 35 on juvenile male 2 .

During focal samples I recorded at two-minute intervals the focal animal's nearest neighbor as well as the number of group members within two meters and within one-half meter of the focal animal. These data could only be collected when the animals were visible. An animal's nearest neighbor was defined as the group member closest to it regardless of the distance between the two. My estimates of $0.5 \mathrm{~m}$ and $2 \mathrm{~m}$ distances were only subjective, but would not have differed for different focal animals. The order in which individuals were sampled was changed daily. There were four possibilities for an animal's nearest neighbor, since the group contained three adults and two juveniles. Infants born in November 1984 were not included as nearest neighbors of the adults in the December sample because they were still being carried. During May and June, focal samples on specific individuals were begun at 90 -minute intervals, while in September-December they were begun at 150 minute intervals.

I then calculated for each half-hour sample the proportion of time that each group member was the focal animal's nearest neighbor, and the mean number of individuals that were within two meters and within one-half meter of the focal animal. I considered each of these proportions and means to be a sample for statistical purposes because runs tests done with Wilcoxon two-sample tests showed that the data collected from focal samples taken at 90-minute intervals on the same individual were statistically independent.

\section{Approach-retreat data}

I recorded approach-retreat interactions of the members of the SW group during 22-28 May 1984 and 11-20 October 1984. During 15-minute samples on focal individuals, I noted all cases of approaches or retreats of the focal animal towards or away from other group members and of other group members towards or away from the focal animal. I scored approaches or retreats when the distance between a pair of animals became less than or greater than 0.5 meters, respectively. After 15 minutes I switched focal animals, in a sequence that changed daily. I did not do focal sampling for approaches and retreats and focal sampling for activities and nearest neighbors at the same time. Up to 27 approaches and retreats combined occurred between particular pairs of animals during 15-minute samples.

From these data I calculated Hinde's proximity index for each pair of individuals (Hinde 1983). This index measures which animal of a pair is more responsible for the maintenance of proximity between them. The proximity index is calculated for individual 1 as follows:

$\left(\frac{\mathrm{Ap} 1}{\mathrm{Ap} 1+\mathrm{Ap} 2} \times 100\right)-\left(\frac{\mathrm{R} 1}{\mathrm{R} 1+\mathrm{R} 2} \times 100\right)$

Ap1 $=$ the number of times animal 1 approached animal 2; Ap2 $=$ the number of times animal 2 approached animal 1 ; $\mathrm{R} 1=$ the number of times animal 1 retreated from animal 2; $\mathrm{R} 2=$ the number of times animal 2 retreated from animal 1

Individual 1 is primarily responsible for the maintenance of proximity if the index is positive, whereas individual 2 is more responsible if the index is negative (Hinde 1983).

Runs tests done with Wilcoxon two-sample tests showed that proximity indices calculated from 15-minute samples adjacent in time were statistically independent. Therefore, I treated these proximity indices as independent samples and calculated the median proximity index for each member of each pair. I then used sign tests to examine the degree to which each median proximity index was statistically different from zero.

\section{Vigilance data}

I labeled the behavior of looking for predators at long distances vigilance behavior. An animal was recorded as exhibiting vigilance only if it sat on an open branch and continually scanned in different directions for at least thirty seconds. I collected vigilance data on two groups. First, I collected data on vigilance over a ten-day period in April 1981, during a total of 63 minutes when some or all members of the $\mathrm{H}$ group were eating the fruits of Duguettia quitarensis (Annonaceae). This fruit tree species was chosen because the trees were sufficiently small and open that all members of tamarin groups in them could usually be observed. I collected data on vigilance behavior only when all four group members were visible. 
I also collected vigilance data on the $198485 \mathrm{SW}$ group during a total of 446 minutes from 2 May through 22 June 1984, and from 25 September 1984 through 24 February 1985. I recorded vigilance only when the majority of the group was feeding on fruits and I could see all individuals. For the 1984-85 SW group data, I totaled the number of minutes that I saw each individual exhibiting vigilance (as defined above) on each of the 30 days that I observed vigilance. I then used the totals for each day as independent samples, and compared the amounts of time that the female and each of the males spent in vigilance with median tests.

\section{Data on other behaviors}

In the SW group in 1984-85, I also recorded all observed copulations, aggressive interactions, food-sharing, and donations of fruits or insects to infants or juveniles. Aggression included fighting, chasing, and agonistic interactions involving aggressive or submissive vocalizations. Displacements not including any of this behavior were not considered aggressive. I considered adults to be sharing food whenever two or more ate from the same individual fruit at the same time. Food transfers involved infants or juveniles receiving (or taking) food from the hands of older group members. Food transfers were recorded for one set of twins born in February 1984 and for one set born in November 1984.

\section{Statistical tests}

All statistical tests reported in this paper were two-tailed, and $P=0.05$ was considered the level of significance. G-tests of goodness of fit used William's correction $\left(\mathrm{G}_{\mathrm{adj}}\right)$. Statistics follow Sokal and Rohlf (1981).

\section{Results}

\section{Grooming patterns}

Saddle-back tamarins spent a considerable amount of time grooming; the $1984 \mathrm{SW}$ group adults were grooming or being groomed by other group members for an average of $9.1 \%$ of their activity budgets $(7.6 \%$ for the adult female, $12.1 \%$ for adult male 1 , and $7.5 \%$ for adult male 2 ). (See Goldizen 1987a for information on collection and analysis of data on activity budgets.)

The adult female of the $1984 \mathrm{SW}$ group received more grooming than she gave, while both adult males gave more grooming than they received (Fig. 1). These data include grooming of and by all group members, including juveniles and infants.

More specifically, all three measures of grooming show that each of the two adult males groomed the female more than she groomed him, although only for male 2 were some of these differences statistically significant (Fig. 2). Both males groomed the female more than they groomed each other, but nonetheless the males groomed together regularly. I observed male 1 groom the female a total
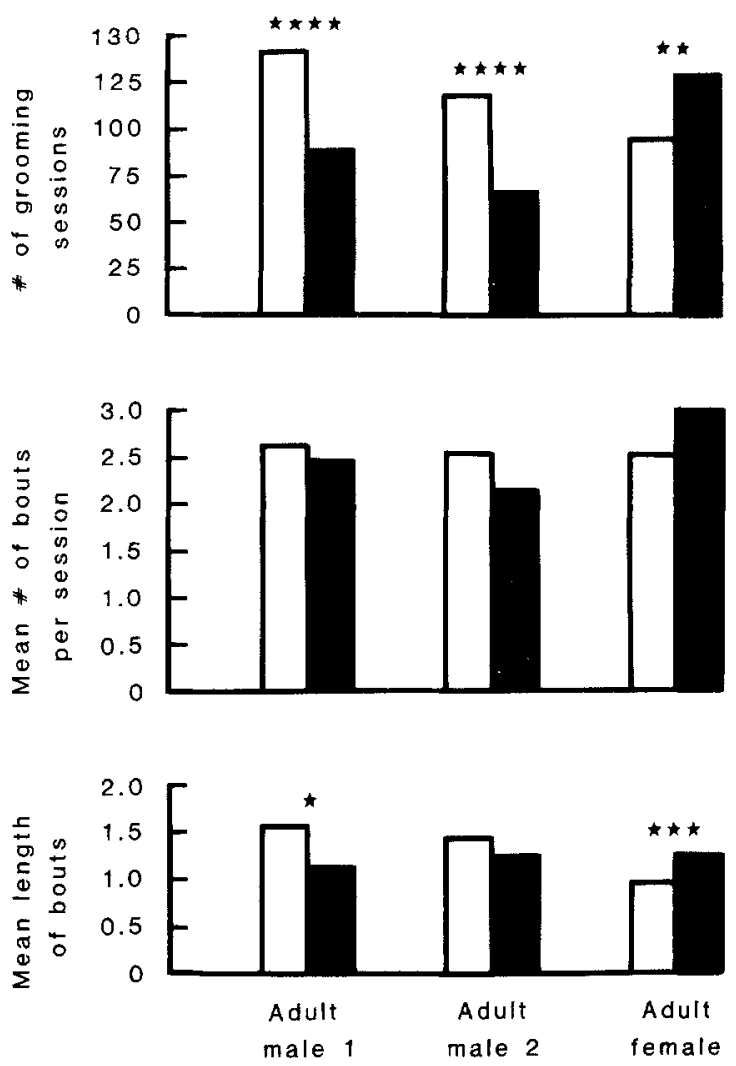

Fig. 1. Three measures of how much grooming each of the 1984 SW group's adults gave compared with how much they received. The measures of grooming are described in the text. Statistical significances of differences in measure 1 were tested with G-tests of goodness of fit using Williams' correction; Mann-Whitney $U$-tests were used for measures 2 and 3. ${ }^{*}=P<$ $0.05, * *=P<0.025, * * *=P<0.005, * * * *=P<0.001$ ( $\square$ Gave grooming, $\square$ Received grooming)

of 301 minutes and groom male 298 minutes, while male 2 groomed the female 386 minutes and groomed male 133 minutes.

Measures 1 (\# of grooming sessions) and 3 (duration of bouts) also showed that adult females received more grooming than they gave in the $\mathrm{H}$ and SW groups in 1980 and 1981 (measure 1 : adult females were groomed by others during 28 sessions and groomed others during 15 sessions, $\mathrm{G}_{\mathrm{adj}}=$ $3.95, P<0.05$; measure 3: 2.2 versus 0.7 mins, Mann-Whitney U-test, $P=0.0821$ ), while adult males gave more grooming than they received (measure 1: adult males groomed others during 54 sessions and were groomed by others during $34, \mathrm{G}_{\mathrm{adj}}=4.55, P<0.05$; measure 3: 1.6 versus 1.2 mins, Mann-Whitney U-test, $P>0.10$ ). Measure 2 (\# of grooming bouts) suggested the opposite trends from measures 1 and 3 for both males (3.9 versus 4.1 bouts) and females (3.4 versus 4.5 

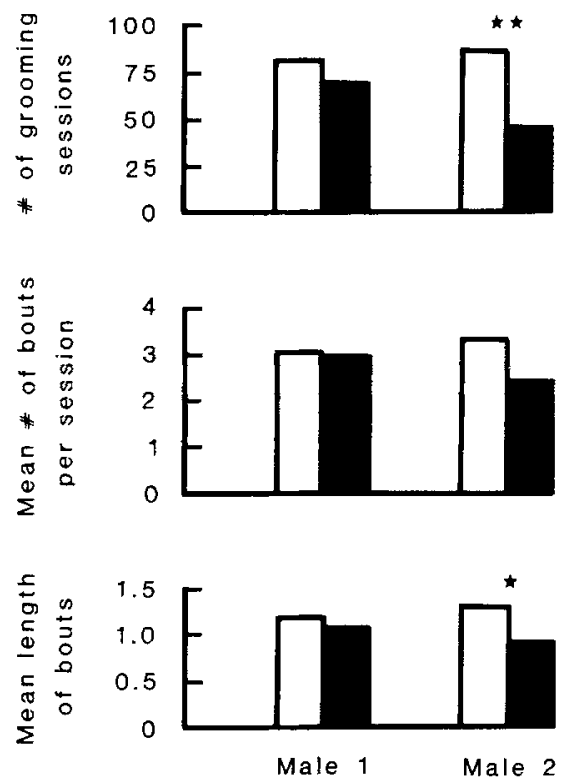

Fig. 2. Three measures of how much each of the 1984 SW group's two adult males groomed the adult female, compared with how much she groomed them. The measures of grooming are described in the text. The statistical significances of differences were tested as described in Fig. 1. ${ }^{*}=P<0.05, * *=P<$ 0.001 ( $\square$ Male grooming female, $\backsim$ Female grooming male)

bouts), but for neither sex was the difference statistically significant.

All three measures of grooming showed that in the 1984-85 SW group both adult males groomed the young (both sets of infants combined) more than did the adult female (Fig. 3). Grooming data collected in 1980 and 1981 from the $H$ group match only in part the patterns found in the SW group in 1984-85. Females were observed grooming young during only six grooming sessions while males were seen doing so during 19 sessions. Individual females groomed young during an average of 1.5 sessions, while males did so during an average of 2.1 sessions. However, during sessions when they did groom young, females groomed young for more bouts than did males (averages of 2.50 versus 2.05) and for longer bouts than did males (averages of 1.62 versus 0.51 minutes). The sample sizes were too small to test these differences for statistical significance.

\section{Spatial relationships in a polyandrous group}

Focal sampling data on the dispersion of the 1984 SW group members showed that this group was quite cohesive. On average, the number of individuals (excluding infants) within two meters of the focal individual was $1.41( \pm 1.02 \mathrm{SD})$ for the fe- male, $1.43( \pm 1.13 \mathrm{SD})$ for male 1 and $1.21( \pm 1.10$ $\mathrm{SD}$ ) for male 2 . (The maximum number possible was 4.) Only the values for the female and male 2 differed significantly (Mann-Whitney U-test, $P=$ 0.0319 ). The average number of group members within 0.5 meters of the focal animal was 0.65 $( \pm 0.82 \mathrm{SD})$ for the female, $0.58( \pm 0.74 \mathrm{SD})$ for male 1 , and $0.56( \pm 0.79$ SD) for male 2 . None of these differences was statistically significant.

From May through December 1984, the female was significantly more often the nearest neighbor of each male than was the other male (Wilcoxon signed-rank tests, $P=0.0074$ for male $1, P=0.0001$ for male 2) (Table 2).

In May 1984 male 1 was significantly more responsible than was the female for the maintenance of spatial proximity between them (proximity index $=-50.0, n=14$ focal samples, $P<0.005$, for female as focal animal). In contrast, male 2 and the female were equally responsible for the mainte-
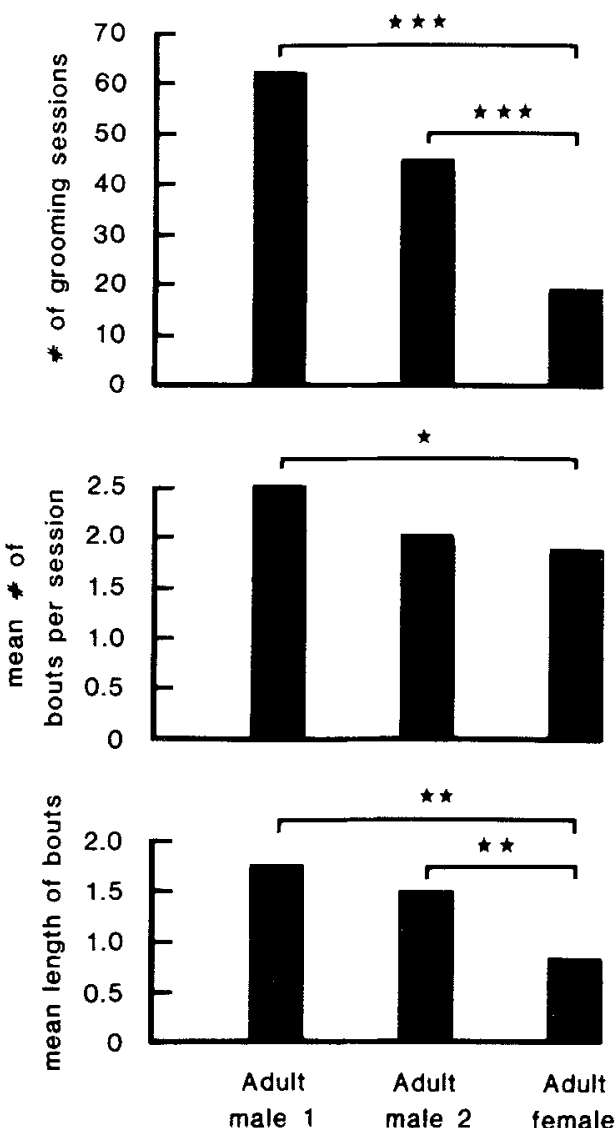

Fig. 3. Three measures of how much the 1984 SW group adults groomed infants and juveniles. Differences in measure 1 were tested for statistical significance with G-tests of goodness of fit using Williams' correction, and differences in measures 2 and 3 were tested with Mann-Whitney U-tests. ${ }^{*}=P<0.05$, $* *=P<0.005, * * *=P<0.001$ 
Table 2. The average percentages of time that each adult group member was the nearest neighbor of each other adult group member in the SW group from May through December 1984. The percentages do not add up to $100 \%$ for each individual because immature group members were often the adults' nearest neighbors

\begin{tabular}{lccc}
\hline \multirow{2}{*}{$\begin{array}{l}\text { Focal } \\
\text { individual }\end{array}$} & \multicolumn{2}{l}{ Nearest neighbor } \\
\cline { 2 - 4 } & Adult male 1 & Adult male 2 & Female \\
\hline Adult male 1 & - & $15.4 \%$ & $24.7 \%$ \\
Adult male 2 & $15.9 \%$ & - & $31.4 \%$ \\
Female & $19.7 \%$ & $34.9 \%$ & - \\
\hline
\end{tabular}

nance of their spatial relationship (proximity in$\operatorname{dex}=0, n=15$ samples, for female as focal animal). In October 1984, male 1 and the female were equally responsible for their proximity (index $=0$, $n=13$ samples, for female as focal animal), whereas male 2 had become significantly more responsible than the female for proximity (index $=-18.3$, $n=24$ samples, $P<0.025$, for female as focal animal). Thus, in this polyandrous trio, either the males acted to remain near the female, or the two sexes did so equally, but the female was not primarily responsible for her spatial relationships to the males during either of the sampling periods.

When the 1984 SW troop's first set of infants were newly weaned and locomoting independently but still dependent on the adults for much of their food, they were frequently the adults' nearest neighbors. At this time, the two infants could not be individually identified. An infant was the nearest neighbor of the female $60.1 \%$ of the time, of male $163.9 \%$ of the time, and of male $256.1 \%$ of the time. There were no statistically significant differences among these values (Mann-Whitney Utests). The data for these comparisons were all collected during focal samples on the adults.

I collected nearest neighbor data on the same animals again when the juveniles were seven to ten months old and had been individually marked. This time I collected data separately for each juvenile. For each of the three adults, I compared how often the two juveniles had been the adult's nearest neighbor. None of these differences were statistically significant (Wilcoxon signed-ranks tests). There was also no significant difference in how often the two juveniles were nearest neighbors of all of the adults combined (Wilcoxon signed-ranks test). Therefore, the data from the two juveniles were combined in the rest of the statistical analyses.

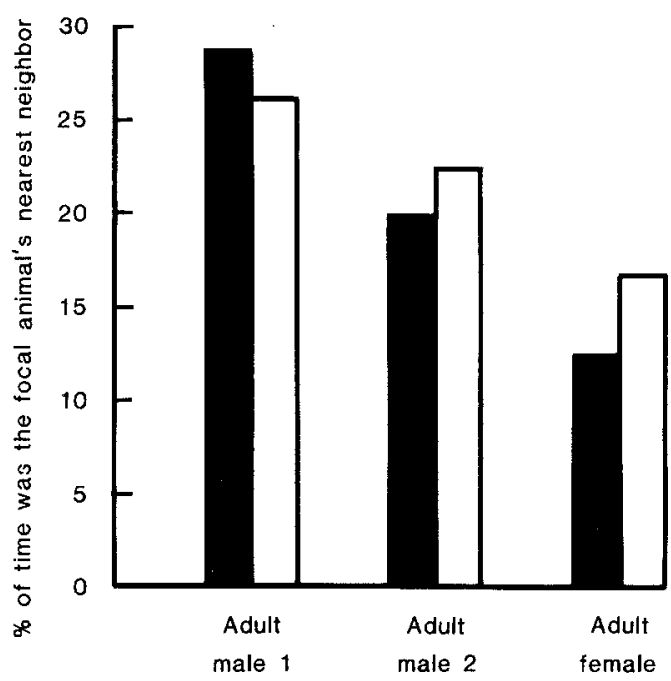

Fig. 4. Percentages of time that the 1984 SW group's seven to ten months old juveniles were the nearest neighbors of the group's three adults (taken from focal samples on the adults) (- Juvenile male 1, $\square$ Juvenile male 2)

At seven to ten months of age the juveniles were the nearest neighbors of adult male 1 most frequently, and of the female least frequently (Fig. 4). They were nearest neighbors of male 1 significantly more often than of male 2 (MannWhitney U-test, $P<0.0001$, and of male 2 significantly more often than of the female (Mann-Whitney U-test, $P=0.0298$ ). Independent data on the nearest neighbors of the juveniles, collected during focal samples on the juveniles, suggest the same trends. Male 1 was the nearest neighbor of the juveniles more than was male 2 and male 2 was marginally more often the juveniles' nearest neighbor than was the female, but neither of these differences were statistically significant.

Proximity indices calculated from data collected when the 1984 SW group's first set of twins was about four months old show that these juveniles were primarily responsible for the maintenance of their proximity to the adults. For each adult-juveniles pair, the median proximity index is negative when calculated for the adults $(-50.0$, $n=28, P<0.005$ for male $1 ;-35.7, n=23, P<$ 0.001 for male $2 ;-58.9, n=25, P<0.001$ for the female). Approach-retreat data collected on the same individuals three and a half months later show a different pattern. At that point the juveniles had been individually marked, so the data are presented separately for each juvenile. Both juveniles were still primarily responsible for maintaining their proximities to male 1 (when male 1 was focal animal: indices $=-22.5, n=24,0.05, P<0.10$ for 
juvenile $1,-50.0, n=26, P<0.005$ for juvenile 2 ). However, the juveniles were no more responsible than were male 2 or the female for their proximity to those adults (in all 4 cases proximity indices $=0$, using 15 to 25 focal samples in each case).

\section{Copulations}

During 1984 and early 1985 , I saw male 1 copulate 25 times and male 2 copulate 31 times with the SW group's single adult female (Goldizen 1987a). Considering only those copulations when I knew the locations of both males, there was no significant difference between the males in how frequently the other male was within 2 meters of the copulating pair ( 7 of male 1's 19 copulations, 13 of male 2's 25 copulations, $\mathrm{G}$ test of independence, $\mathrm{G}=1.02, P>0.1$ ).

The males exhibited agonistic behavior toward each other during only three of the 20 copulations when the males were less than two meters apart; in all three cases male 2 attempted (apparently unsuccessfully) to prevent male 1 from copulating by gently trying to push him off the female. The other 17 times, the non-copulating male showed no obvious reaction to the copulation. The three copulations that involved aggression all occurred between September 15 and 18, when the female was pregnant (see below).

I observed seven times which individual approached the other immediately preceeding copulations; the male always approached the female. This does not preclude the possibility that the female somehow signalled her interest in copulating to the male, but during the 56 copulations I witnessed in this group (Goldizen 1987a), I never saw or heard anything that resembled a presentation or an invitation (such as tongue-flicking) to copulate on the female's part.

\section{Aggression}

I observed only 17 aggressive incidents between the 1984-85 SW group's two polyandrous males during 587 hours of observation. Fourteen of these occurred during two periods when one or both males appeared especially interested in the female [June 6-8 $(n=1)$ and September 14-18 $(n=13)]$. However, even during these episodes, the aggressive incidents between the males were relatively mild, usually involving only chasing and gentle pushing. The other three cases of aggression occurred when male 2 tried to feed from a fruit that male 1 was feeding from. I observed the two males
Table 3. Numbers of food items transferred from the three adults of the $1984 \mathrm{SW}$ group to the group's two sets of young

\begin{tabular}{lllll}
\hline Recipients & Food type & \multicolumn{2}{l}{ Donor } \\
\cline { 3 - 5 } & & Male 1 & Male 2 & Female \\
\hline $\begin{array}{l}\text { Young born in } \\
\text { February 1984 }\end{array}$ & Insects & 34 & 16 & 20 \\
& $\begin{array}{l}\text { Fruits and } \\
\text { fruit parts }\end{array}$ & 33 & 21 & 37 \\
$\begin{array}{l}\text { Young born in } \\
\text { November 1984 }\end{array}$ & Insects & 13 & 5 & 5 \\
& $\begin{array}{l}\text { Fruits and } \\
\text { fruit parts }\end{array}$ & 6 & 3 & 3 \\
\hline
\end{tabular}

eating simultaneously from the same fruit without any aggression on six other occasions.

Aggression between males and females occurred rarely, in four contexts. (1) During the 587 hours that I observed the 1984-85 SW group, seven aggressive incidents between the female and either of the males occurred over insects or lizards. Six of these occurred during the 14-18 September period when both males were intensely chasing and attempting to copulate with the pregnant female (Goldizen 1987a). (2) I twice saw the female respond aggressively when male 2 tried to take an infant off her back. (3) During the 14-18 September period, the female snapped at the males many times (although not quantified). It appeared as though the close following of the female by the males during this period was interfering with her ability to feed, insect-forage and rest. (4) During one intergroup encounter I saw male 1 chase and attack the female of his own group.

\section{Food transfers}

From about 2 to 8 months of age, young tamarins received fruits, insects, and occasional vertebrate prey from subadult and adult group members. These transfers from older to younger animals ranged along a continuum from what appeared to be voluntary food sharing on the part of the older animal to the younger individual taking food away from the older one. With young infants, food transfers were usually of the first type, whereas with older juveniles they were mostly the second type.

Both sets of offspring in the 1984 SW group received more insects from adult male 1 than they did from the female or from adult male 2 (Table 3 ). These figures only approximate the biomass of 
Table 4. Means $( \pm S D)$ of numbers of minutes that each of the 1984-85 SW group adults was recorded as exhibiting vigilance behaviour per day during two times of the year*

\begin{tabular}{lcll}
\hline Sample period & Male 2 & Male 1 & Female \\
\hline 2 May- & $6.31 \pm 5.77$ & $4.06 \pm 5.69$ & $2.12 \pm 3.67$ \\
22 June 1984 & & & \\
25 September 1984- & $11.79 \pm 7.38$ & $5.36 \pm 5.23$ & $4.14 \pm 6.16$ \\
24 February 1985 & & & \\
\hline
\end{tabular}

* The averages presented in this table represent only small proportions of the times that animals spent in vigilance, because I recorded the data only under the specific conditions described in the methods section

insect material transferred because the insects ranged from those one or two centimeters in length to fat orthopterans about five centimeters long. However, these data show that the offspring received insects from all three adults.

Infants and juveniles also received whole fruits and parts of fruits from all three adults (Table 3). As with transfers of insects, these results should only be considered rough approximations of the patterns of fruit-transfers to infants, because the fruits varied substantially in size and nutritional value.

\section{Vigilance}

During the 63 minutes of data on vigilance behavior collected while the $1981 \mathrm{H}$ territory group was eating Duguettia quitarensis, the four group members spent the following numbers of minutes in vigilance behaviour: 37 for the adult male, 33 for the adult female, 31 for the subadult female, and 3 for the juvenile male.

In the 1984-85 SW group, male 2 spent the most time exhibiting vigilance behavior, and the female the least, during both May-June 1984 and September 1984-February 1985 (Table 4). Male 2 spent significantly more time than the female showing vigilance behavior during both samples (Median tests; $n=16$ days, $P=0.0225 ; n=14$ days, $P=0.0002)$; the differences between male 1 and the female were not significant during either sample.

\section{Discussion}

Aggressive incidents were uncommon between the two polyandrous males of the 1984-85 SW group; in fact, these two exhibited a very cooperative relationship. They groomed each other, occasionally shared food items, and both cared for the same two sets of infants. There was no evidence of a dominant-subordinate relationship between these males; they appeared to share quite equally in social and sexual access to the female, as well as in infant-carrying (Goldizen 1987a). My subjective impression is that the relationships between the males of several other multi-male groups in the population were also more cooperative than agonistic. Unfortunately the relatedness of most pairs of polyandrous males was not known, although one pair not discussed here almost certainly consisted of unrelated males (Terborgh and Goldizen 1985).

The period during which these two males most overtly competed with each other for access to the female occurred two-thirds of the way through her pregnancy. It was only during this period that the males tried to prevent each other from copulating, and most of the other aggressive incidents between them also occurred at this time. A similar period of a few days of increased sexual interest and activity in mid-pregnancy has been seen in several captive golden-lion tamarin (Leontopithecus rosalia) groups (Kleiman and Mack 1977).

Epple (1972) reported that severe aggression sometimes occurred between the males of captive two-male one-female trios of $S$. fuscicollis. I suggest that aggression will be rare between polyandrous males only when polyandry increases their fitness, as proposed for wild S. fuscicollis in some circumstances (Terborgh and Goldizen 1985; Goldizen 1987a). Male saddle-back tamarins in captivity would rarely benefit from being polyandrous because the energetic costs of infant care are so much lower in typical captive situations than in the wild. Thus it is not surprising that severe aggression can occur when two males are housed in the same cage with a single female. It is also possible that there would be less aggression between pairs of related males than between unrelated males, although it is not clear whether Epple's experiments involved related or unrelated males.

The differences in the relationships between polyandrous males in Tasmanian native hens and dunnocks may also be explained by the reproductive benefit (or lack thereof) of polyandry to the males. In dunnock groups, dominant males do not benefit from being polyandrous (Davies and Lundberg 1984; Davies 1986), and polyandrous males often fight, the alpha male guards the female before and after egg-laying, and the males disrupt each others' copulations (Davies 1985). Tasmanian native hen males, on the other hand, appear to benefit from polyandry (via increased inclusive fit- 
ness because polyandrous males are usually closely related; Ridpath 1972 b, Maynard Smith and Ridpath 1972). In this species, aggression among group members is rare, both males copulate, and there is no evidence of dominance hierarchies among males.

The relationships between polyandrous males have been described for some other bird species. In acorn woodpeckers (Melanerpes formicivorous), Stacey (1979) found almost no aggression among group members in one population, although Joste et al. (1982) found clear dominance interactions between the two males of a group in a different population. Koenig and Mumme's (1987) data show that males who share a female with one or two other males have higher fitness than do those who nest singly. In dusky moorhens (Gallinula tenebrosa) there is no evidence of dominance hierarchies among group members, all males copulate about equally frequently, and aggression among group members is rare (Garnett 1978, 1980). In pukekos (Porphyrio porphyrio), male dominance hierarchies are evident and subordinate males are sometimes unable to complete copulations if dominant males are nearby. However, there was no relationship between males' dominance ranks and their copulation frequencies (Craig 1980; Jamieson and Craig 1987). Further studies are needed on these last two species to elucidate the connections between the relationships exhibited by polyandrous males and the effect of polyandry (or polygynandry) on the fitness of males.

The data reported here suggest that, in at least one polyandrous $S$. fuscicollis group, the males were more responsible than the female for the maintenance of pairbonds. The males groomed the female more than the reverse, they approached the female more often and retreated from her less often than did the female towards the males, and the males rather than the female apparently initiated copulations. Further data on wild saddle-back tamarins are needed to know whether these are general trends.

There are very few data on social relationships between males and females in bird species that exhibit cooperative polyandry. In Tasmanian native hens and dusky moorhens, $79 \%$ and $86 \%$, respectively, of sexual displays were initiated by females (Ridpath 1972a; Garnett 1978), but in the native hens a display given when members of a pair approached each other from a distance was done equally often by males and females (Ridpath 1972a). In pukekos, females allopreened males more than the reverse, but males courtship-fed females more than females did males. Females some- times solicited copulations; they also terminated copulation attempts more often than did males (Craig 1980). In dunnocks, monogamous males and alpha males of trios guarded females closely beginning several days before egg-laying. In trios, females actively attempted to evade the alpha male and often solicited copulations from the beta male (Davies 1983).

The division of labor between the sexes appears to differ for different kinds of offspring care in saddle-back tamarins. Females are responsible for all of the energetic costs of gestation and lactation, but adult males do approximately twice as much infant-carrying as do females (Goldizen 1987a), and infant-carrying is almost certainly more costly than any other form of parental care in tamarins, except for lactation (Terborgh and Goldizen 1985; Goldizen 1987a). In the 1984-85 SW group, the males also groomed the offspring and remained in close proximity to them more than did the female, and spent more time in vigilance behavior than the female, although this difference was significant only for one of the males. The infants and juveniles obtained insects and fruits from all three of the group's adults, as seen in another group in this population (Terborgh and Goldizen 1985), a wild group of buffy-headed marmosets (Callithrix flaviceps) (Ferrari 1987) and captive goldenlion tamarins (Brown and Mack 1978). It is not possible to compare quantitatively the total parental investments of male and female tamarins, because of the difficulty of comparing the energetic costs and risks of different forms of parental care. However, it is at least clear that in this species both sexes invest heavily in offspring.

Very little data exist on parental investment patterns in other wild populations of callitrichids, though the division of infant-carrying among group members in one group of wild moustached tamarins $(S$. mystax) appeared similar to that of S. fuscicollis (Garber 1986). An abundance of data on parental care in captive callitrichids show that substantial parental investment by both sexes is typical of this primate family (e.g., Epple 1975; Vogt et al. 1978; Cebul and Epple 1984 for S. fuscicollis; Snowdon and Soini, in press, for review of other species). McGrew (1988) found that in cotton-top tamarins (Saguinus oedipus), the relative magnitudes of maternal and paternal care depend on the number of nonreproductive helpers in the group.

A review of the literature suggests that in most bird species with cooperatively polyandrous groups both males and females invest considerably in offspring (Tasmanian native hen, Ridpath 
1972a; dusky moorhen, Garnett 1978; dunnock, Houston and Davies 1985, Davies 1985, 1986; pukeko, Craig 1980; acorn woodpecker, Koenig et al. 1983). In Galapagos hawks (Buteo galapagoensis) and Harris hawk (Parabuteo unicinctus) females may contribute more parental care than males (DeVries 1975; Mader 1979). Unfortunately, quantitative data on all aspects of parental care do not exist for most of these species.

The data presented here on saddle-back tamarins are only preliminary, because of the small number of animals studied. However, these data suggest that similar detailed studies of social relationships in other species that exhibit cooperative polyandry would greatly increase our understanding of the causes and consequences of facultatively polyandrous mating patterns.

Acknowledgements. I thank John Terborgh for introducing me to the tamarins and helping me throughout this study. F. Cornejo, R. Evans, C. McVay, B. Mitchell, N. Muckenhirn, P. Neyman, T. Porras, M. Reichman, P. Stern and C. Wise helped in the field. P.R. Grant, B.A. Hazlett, W. Holmes, B. Rathcke, B. Smuts, M. Symington, J. Terborgh, R.W. Wrangham and anonymous reviewers kindly helped me with earlier drafts of the manuscript. Permission to use the Cocha Cashu Biological Station was graciously extended by the Direccion General Forestal y de Fauna of the Peruvian Ministry of Agriculture and the staff of the Manu National Park. This work was supported by NSF grants DEB79-04750 and BNS79-15079 to John Terborgh and by the following grants to the author: NSF Grant BSR-8311782, Grant \#4499 from the Wenner-Gren Foundation for Anthropological Research, an Edwin Edwards Scholarship and Block grants from the University of Michigan, a Charles Tobach Award from the T.C. Schneirla Research Fund, a Grant-in-Aid of Research from Sigma Xi - the Scientific Research Society, and Grant No. 220 of the Joseph Henry Fund of the National Academy of Sciences.

\section{References}

Altmann J (1974) Observational study of behavior: sampling methods. Behaviour 49:227-267

Brown JL (1987) Helping and communal breeding in birds: Ecology and evolution. Princeton University Press, Princeton

Brown D, Mack DS (1978) Food sharing among captive Leontopithecus rosalia. Folia Primatol 29:268-290

Cebul MS, Epple G (1984) Father-offspring relationships in laboratory families of saddle-back tamarins (Saguinus fuscicollis). In: Taub DM (ed) Primate paternalism. van Nostrand Reinhold, New York, pp 1-19

Craig JL (1980) Pair and group breeding behaviour of a communal gallinule, the pukeko, Porphyrio p. melanotus. Anim Behav 28:593-603

Crook JH, Crook SJ (1988) Tibetan polyandry: Problems of adaptation and fitness. In: Betzig L, Borgerhoff Mulder $M$, Turke $P$ (eds) Human reproductive behavior: A Darwinian analysis. Cambridge University Press, Cambridge

Davies NB (1983) Polyandry, cloaca pecking, and sperm competition in dunnocks. Nature $302: 334-336$
Davies NB (1985) Cooperation and conflict among dunnocks, Prunella modularis, in a variable mating system. Anim Behav $33: 628-648$

Davies NB (1986) Reproductive success of dunnocks, Prunella modularis, in a variable mating system. I. Factors influencing provisioning rate, nestling weight and fledging success. J Anim Ecol 55:123-138

Davies NB, Houston AI (1986) Reproductive success of dunnocks, Prunella modularis, in a variable mating system. II. Conflicts of interest among breeding adults. J Anim Ecol 55:139-154

Davies NB, Lundberg A (1984) Food distribution and a variable mating system in the dunnock, Prunella modularis. J Anim Ecol 53:895-912

De Vries T (1975) The breeding biology of the Galapagos hawk, Buteo galapagoensis. Le Gerfaut 65:29-57

Durham WH (1988) Coevolution: genes, culture and human diversity. Stanford University Press, Stanford (in press)

Epple G (1972) Social behavior of laboratory groups of Saguinus fuscicollis. In : Bridgewater PD (ed) Saving the lion marmoset. Proc WAPT Golden Lion Marmoset Conference, WAPT, Oglebay Park, Wheeling, pp 50-58

Epple G (1975) Parental behavior in Saguinus fuscicollis ssp. (Callitrichidae). Folia Primatol 24:221-238

Epple G, Katz Y (1980) Social influences on first reproductive success and related behaviors in the saddle-back tamarin (Saguinus fuscicollis, Callitrichidae). Int J Primatol 1:171-183

Faaborg J, Patterson CB (1981) The characteristics and occurrence of cooperative polyandry. Ibis $123: 477-484$

Ferrari SF (1987) Food transfer in a wild marmoset group. Folia Primatol 48:203-206

Garber PA (1986) Social organization and patterns of infant transport in Saguinus mystax in Amazonian Peru. Primate Report 14:78

Garnett ST (1978) The behaviour patterns of the dusky moorhen, Gallinula tenebrosa Gould (Aves: Rallidae). Aust Wildl Res 5:363-384

Garnett ST (1980) The social organization of the dusky moorhen, Gallinula tenebrosa Gould (Aves: Rallidae). Aust Wild Res 7:103-112

Gengozian N, Batson JS, Smith TA (1978) Breeding of marmosets in a colony environment. Primates Med 10:71-78

Goldizen AW (1987a) Facultative polyandry and the role of infant-carrying in wild saddle-back tamarins (Saguinus fuscicollis). Behav Ecol Sociobiol 20:99-109

Goldizen AW (1987b) Tamarins and marmosets: communal care of offspring. In: Smuts BB, Cheney DL, Seyfarth RM, Wrangham RW, Struhsaker TT (eds) Primate societies. University of Chicago Press, Chicago, pp 33-43

Goldizen AW (1988) Tamarin and marmoset mating systems: unusual flexibility. Trends Ecol Evol 3:36-40

Hinde RA (1983) Development and dynamics. In: Hinde RA (ed) Primate social relationships: an integrated approach. Sinauer, Sunderland, pp 65-70

Houston AI, Davies NB (1985) The evolution of cooperation and life history in the dunnock, Prunella modularis. In: Sibley RM, Smith RH (eds) Behavioral ecology: ecological consequences of adaptive behavior. Blackwell, Oxford, pp 471-487

Jamieson IG, Craig JL (1987) Dominance and mating in a communal polygynandrous bird: cooperation or indifference towards mating competitors? Ethology 75:317-327

Joste NE, Koenig WD, Mumme RL, Pitelka FA (1982) Intragroup dynamics of a cooperative breeder: an analysis of reproductive roles in the acorn woodpecker. Behav Ecol Sociobiol 11:195-201 
Kleiman DG, Mack DS (1977) A peak in sexual activity during mid-pregnancy in the golden lion tamarin, Leontopithecus rosalia (Primates: Callitrichidae). J Mammal 58:657660

Koenig WD, Mumme RL (1987) Population ecology of the cooperatively breeding acorn woodpecker. Princeton University Press, Princeton

Koenig WD, Mumme RL, Pitelka FA (1983) Female roles in cooperatively breeding acorn woodpeckers. In: Wasser SK (ed) Social behavior of female vertebrates. Academic Press, New York, pp 235-261

Mader WJ (1979) Breeding behavior of a polyandrous trio of Harris' hawks in southern Arizona. Auk 96:776-788

Maynard Smith J, Ridpath MG (1972) Wife sharing in the Tasmanian native hen (Tribony $x$ mortierii) : a case of kinship selection? Am Nat 106:447-452

McGrew WC (1988) Parental division of infant caretaking varies with family composition in cotton-top tamarins. Anim Behav 36:285-286

Oring LW (1986) Avian polyandry. In: Johnston RF (ed) Current ornithology. Plenum Press, New York, pp 309-351

Ridpath MG (1972a) The Tasmanian native hen, Tribonyx mortierii. I. Patterns of behaviour. CSIRO Wildlife Res $17: 1-51$

Ridpath MG (1972b) The Tasmanian native hen, Tribonyx mortierii. II. The individual, the group, and the population. CSIRO Wildlife Res 17:53-90

Snowdon CT, Soini P (1988) The tamarins: genus Saguinus. In: Mittermeier RA, Coimbra-Filho AF (eds) Ecology and behavior of neotropical primates, vol 2. Academia Brasileira de Ciencias, Rio de Janeiro (in press)

Sokal RR, Rohlf FJ (1981) Biometry. Freeman, San Francisco

Stacey PB (1979) Kinship, promiscuity and communal breeding in the acorn woodpecker. Behav Ecol Sociobiol 6:53-66

Sussman RW, Kinzey WG (1984) The ecological role of the Callitrichidae: A review. Am J Phys Anthropol 64:419-449

Terborgh J (1983) Five new world primates: a study in comparative ecology. Princeton University Press, Princeton

Terborgh J, Goldizen AW (1985) On the mating system of cooperatively breeding saddle-back tamarins (Saguinus fuscicollis). Behav Ecol Sociobiol 16:293-299

Vogt JL, Carlson H, Menzel E (1978) Social behavior of a marmoset (Saguinus fuscicollis) group. I. Parental care and infant development. Primates 19:715-726 